the facts are that they thereby discovered 'Pluto'. Pluto is a code name. Protactinium also starts with a ' $P$ '.... Perhaps the others have used protactinium: this is almost easier to imagine than all other methods.”

What a different light this quotation throws on what Heisenberg and his colleagues "knew" about element 94.

Churchill is reputed to have said "man will occasionally stumble over the truth, but usually manages to pick himself up, walk over or around it, and carry on". How apt a description of Walker's writings on the German atomic bomb project.

Irving Klotz is in the Department of Chemistry, Northwestern University, Evanston, Illinois 60208-3113, USA.

\section{Who enforces the law?}

\author{
Giovanni F. Bignami
}

Idee per II governo: L'Universita. By Raffaele Simone et al. Laterza: 1995. Pp. 187. L15,00O.

II peso della qualita accademica. By S. Garbisa and L. Calza. Cleup: 1995. Pp. 123. L18,000.

WE are fortunate to have Laterza's series of books on 'Idee per il governo'. The latest addition, a small paperback on Italian universities, is a natural follow-up to Carlo Bernardini's earlier volume on scientific research in Italy. The author of the present tome is Raffaele Simone, an old hand in castigating Italian academic institutes and their members. The book could hardly be more timely (no doubt by chance): for the first time, about 50 concorsi (nationwide competitions for professorships) are being scrutinized by magistrates for alleged corruption and abuse of office - a scandal recently given wide coverage by the Italian mass media. This is a welcome development: until now, spectacular unfairness and even gross fraud have been consistently perpetrated with guaranteed impunity.

Nature has championed a just cause by publishing reports of several of these scandals, as well as correspondence on the subject, notably from Fernando Aiuti and colleagues and from Spiridione Garbisa and Laura Calza (the authors of the second book under consideration). Two recent news items are particularly enlightening, particularly on the end of what used to be a true omertà wall (see Nature 374, 756 \& $378,228 ; 1995)$

Simone does more than simply stimulate an analysis of what went wrong - and is still wrong - with Italian universities; in convening a group of experts, in the poignant style of the series, he also brings forward proposals for improvement. A possible starting point is suggested in the contribution by Tullio De Mauro, who makes a simple but arresting observation. There are currently 85 institutions across the world that have survived more-or-less unchanged for over five centuries. Among these are the Roman Catholic Church, the British parliament, several Swiss cantons and the Monte dei Pashi of Siena. But most (more than 70) are universities, many in Italy.

Even in Italy, the message is that universities are here to stay, although sooner or later they will have to be brought, for good or bad, in line with the evolution of Italian society. To this end, Simone lists 11 detailed tasks facing the reformer in raising the Italian university to the level he sadly calls "just about decent". It seems getting there will be a long uphill trek, given the lowlands we are in now.

Aother contributor is Antonio Ruberti, a former minister for universities and European commissioner. During his short ministry, Ruberti succeeded in having approved by parliament a package of four laws providing a framework, and some political guidance, for raising the Italian university system to a modern, European level. Some five years later, they are still largely waiting to be applied. It would seem that the cause is the usual inextricable battle for responsibility between the ministry in Rome, always fearful of losing control (that is, power), and individual universities, autonomous sometimes in thought but rarely in practice. Nowhere is Dante's splendid hendecasyllable "Le leggi son, una chi pon mano ad esse?" (poorly rendered, "Laws do exist, but who'll stand to enforce them?") more applicable.

Or is the culprit simply indifference, in a political and media environment that has lost all sense of perspective for anything cultural? Riccardo Chiaberge, a brilliant columnist of the Corriere della Sera, raises this suggestion. The words autonomia universitaria, he argues, are by now a kind of "mantra", an "om $m a n i$ pad me hum" (erroneously here interpreted as sanskrit), mechanically repeated without pause to grasp its actual meaning.

All the contributors agree that too much visibility is given to the concorsi scandals, and that this exposure artfully hides deeper, more fundamental problems in the higher-education system of a country still coming up for air after 20 years of fascism followed by 40 years of uninterrupted, rigorous rule by the Christian Democrats.

Nevertheless, professors have to be enrolled, and the fairer the means, the better. Here Garbisa and Calza's book should come in handy. It is, as the title says, a tool for judging academic quality through the use of "objective parameters". This little volume should be read literally to the last page: the last four contain an illuminating and complete bibliography on the concorsi topic as well as on justice (or injustice) in Italian universities, listing a total of 76 items. (Here Nature, with 23 entries, scores about as high as all the Italian daily and weekly publications together.) Most Italian scientists are familiar with such parameters as the citation index and impact factor. But with alarming frequency these notions seem to escape their minds when it is their turn to sit as members of a concorso commission. So it is appropriate, then, that the authors remind everyone that there are methods for an objective evaluation of candidates by competent and honest peer review, that no magic is needed and that commissions, if honest, simply cannot commit gross injustice if they follow such methods. They add a selection of clear examples to avoid misunderstandings by those who still find such modern intricacies difficult to grasp.

Gilberto Muraro, rector magnificus of Padua University (one of the venerable institutions mentioned above) makes it clear: that it is only on the basis of bibliometric methods such as those described in this booklet that we can ever hope to enrol professors fairly and, in the end, fruitfully. No desperate, last-ditch battle for every concorso, but also no room for the dreaded ope legis, promotion by virtue of law, always lurking in some of the dark corridors of power.

Giovanni F. Bignami is at the Istituto di Fisica Cosmica CNR, 15 via Bassini, 20133 Milano, Italy.

\section{Correction}

The correct spelling of the name of the editor of Aristophanes' Birds reviewed by Malcolm Davies in Nature 379, 307-308; 1995) is Nan Dunbar.

New in paperback

\section{Facing the Future: The Case for} Science by Michael Allaby. Bloomsbury, £7.99. A passionate effective counterblast to the recent public backlash against science. The author is especially good on environmentalism, his home turf, exposing as nonsense many current fears about global warming, nuclear power, pesticides and pollution.

The Spirit of the System: Lamarck and Evolutionary Biology by Richard W. Burkhardt, with a new opening by the author. Harvard University Press,

$\$ 17.95, £ 11.50$. "It is a great relief to have at last a good book on Lamarck in English, neither partisan through patriotism, nor distorted by dislike of Darwin. Burkhardt gives us an excellent introduction to Lamarck, his contemporaries and predecessors, and to the scientific bodies and institutions in revolutionary Paris... Exceptionally well written" wrote A. J. Cain in a review of the original edition in Nature. 